\title{
Localized Castleman disease
}

INSERM

\section{Source}

INSERM. (1999). Orphanet: an online rare disease and orphan drug data base. Localized

Castleman disease. ORPHA:93685

Localized Castleman disease (LCD) is the most common form of Castleman disease (CD; see this term) and it is usually asymptomatic or it may present with enlarged lymph nodes. LCD may be cured by surgical resection. 